Document downloaded from:

http://hdl.handle.net/10251/155057

This paper must be cited as:

Vague Cardona, JJ.; Melgarejo-Lermas, JC.; Boria Esbert, VE.; Guglielmi, M.; Moreno Cambroreno, MDR.; Reglero Mangada, MS.; Mata-Sanz, R.... (2019). Experimental Validation of Multipactor Effect for Ferrite Materials Used in L- and S-Band Nonreciprocal Microwave Components. IEEE Transactions on Microwave Theory and Techniques. 67(6):2151-2161. https://doi.org/10.1109/TMTT.2019.2915546

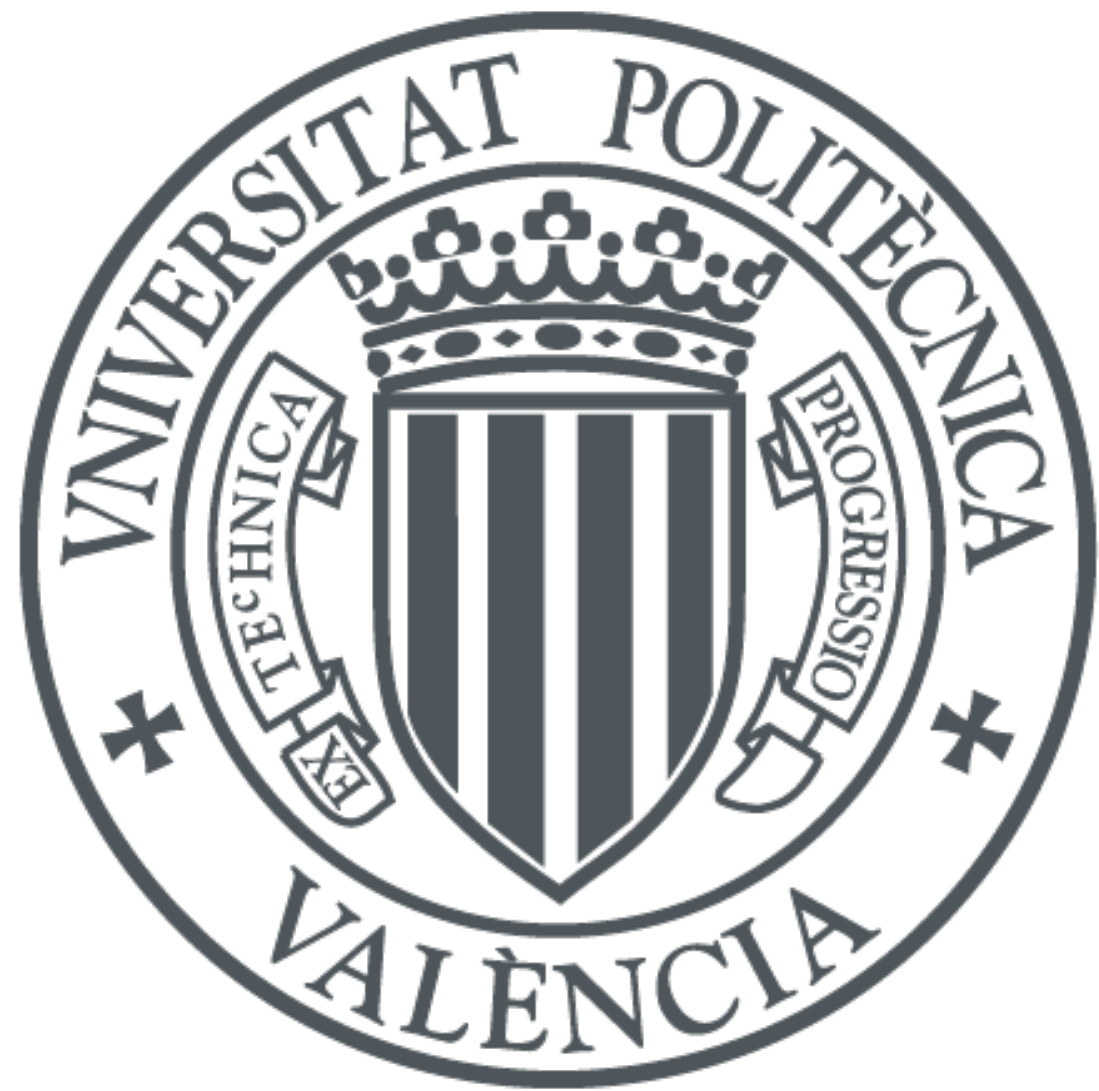

The final publication is available at

https://doi.org/10.1109/TMTT.2019.2915546

Copyright Institute of Electrical and Electronics Engineers

Additional Information 


\title{
Experimental Validation of Multipactor Effect for Ferrite Materials Used in L- and S-Band Non-Reciprocal Microwave Components
}

\author{
J. Vague, J.C. Melgarejo, V.E. Boria, Fellow, IEEE, M. Guglielmi, Fellow, IEEE, R. Moreno, \\ M. Reglero, R. Mata, I. Montero, D. González-Iglesias, B. Gimeno, Member, IEEE, Á. Gómez, \\ Á. Vegas, Member, IEEE, and D. Raboso
}

\begin{abstract}
This paper reports on the experimental measurement of power threshold levels for the multipactor effect between samples of ferrite material typically used in the practical implementation of $\mathbf{L}$ - and S-bands circulators and isolators. For this purposes, a new family of wide-band, non-reciprocal rectangular waveguide structures loaded with ferrites has been designed with a full-wave electromagnetic simulation tool. The design includes also the required magneto-static field biasing circuits. The multipactor breakdown power levels have also been predicted with an accurate electron tracking code using measured values for the Secondary Electron Yield (SEY) coefficient. The measured results agree well with simulations thereby fully validating the experimental campaign.
\end{abstract}

Index Terms - Ferrites, ferromagnetic resonance, Gadolinium-Aluminum garnet, Holmium garnet, multipactor, space applications, wideband non-reciprocal devices.

Manuscript received Month Day, Year; revised Month Day, Year; accepted Month Day, Year.

This work was supported by European Space Agency (ESA) through research project "Novel Investigation in Multipactor Effect in Ferrite and other Dielectrics used in High Power RF Space Hardware" (ref. AO 1 7551/13/NL/GLC), and by MINECO (Spanish Government) under R\&D projects TEC2016-75934-C4-1-R, TEC2016-75934-C4-2-R and the ERDF co-funded project TEC2014-55463-C3-3-P.

This paper is an expanded version from the IEEE MTT-S International Conference on Numerical Electromagnetic and Multiphysics Modeling and Optimization NEMO-2018, August 8-10, 2018, Reykjavik, Iceland. (Corresponding author: Joaquín Vague).

J. Vague, J.C. Melgarejo, V.E. Boria, M. Guglielmi and M. Reglero are with Universitat Politecnica de Valencia, E-46022, Valencia, Spain. (e-mail: jvague@dcom.upv.es, vboria@dcom.upv.es,marco.guglielmi@iteam.upv.es)

R. Moreno is with Val Space Consortium (VSC), Ciudad Politécnica de la Innovación, E-46022, Valencia, Spain.

D. Gónzalez Iglesias, B. Gimeno and R. Mata are with Department of Applied Physics and Electromagnetism, Instituto de Física Corpuscular and Instituto de Ciencia de Materiales, Universidad de Valencia, E-46100, Burjassot (Valencia), Spain.

I. Montero is with Instituto de Ciencia de Materiales de Madrid, Consejo Superior de Investigaciones Científicas (CSIC), E-28049 Madrid, Spain.

Á. Gómez, and Á. Vegas are with Departamento de Ingeniería de Comunicaciones, Universidad de Cantabria, E-39005 Santander, Spain.

D. Raboso is with European Space Research and Technology Centre of the European Space Agency (ESTEC-ESA), Noordwijk, The Netherlands.

\section{INTRODUCTION}

GERRITES are ceramic materials that are commonly used in a wide number of radio frequency (RF) and high-frequency devices [1]. In this context, a large variety of ferrite geometries and material compositions are currently available in the market. A very common type of ferrite material are garnets. These advanced soft ferrites that are used in a great variety of microwave components operating from $100 \mathrm{MHz}$ to $40 \mathrm{GHz}[2]$.

Ferrites are used, for instance, to mitigate electromagnetic (EM) interferences and to implement radar absorbing materials (RAMs) [3]. This type of application is made possible by the fact that ferrites can very effectively absorb microwave signals. It is, in fact, well known that when ferrites are operating near their ferromagnetic resonance [4], they exhibit low conductivity (as dielectric materials) and high losses, due to a strong interaction with the penetrating EM fields. Moreover, ferrite materials, biased well above saturation, exhibit a non-reciprocal high-frequency response that has been extensively used in many different microwave components, such as isolators, circulators, gyrators, phase shifters and switches [5]-[7]. The non-reciprocal behaviour of ferrites can be effectively modelled considering non-diagonal terms in the permeability tensor of the (magnetized) ferrite [8].

To maximize the interaction between ferrites and the EM fields in non-reciprocal microwave components, it is customary to place the ferrite samples in high EM field regions. This, in turn, may trigger a multipactor discharge in applications operating under high vacuum conditions (e.g. satellite payloads, particle accelerators and klystrons).

Multipactor is a well-known electron avalanche effect that can have very destructive effects and must therefore be effectively avoided in all RF and microwave devices for satellite communication payloads [9]. It is, in fact, well-known that, under vacuum conditions, free electrons can be driven by high-level $\mathrm{RF} /$ microwave EM fields to impact the surface of materials that can emit new secondary electrons, thus provoking a resonant electron avalanche that can have very 
severe effects [10]. Among them, increased reflection and insertion losses, signal distortion and even physical damage.

The multipactor discharge depends on a number of factors such as the geometry of the device, the surface properties of the materials, and the power level of the microwave signal [11]. Traditionally, this discharge phenomenon has been studied considering a parallel plate model [12]. This simple model has been widely used in research works [10], [13], and in industry standards [9], [14].

The simple parallel plate approach has also been used to model the multipactor effect in a waveguide containing magnetized ferrite [15], [16]. However, realistic nonreciprocal microwave components (e.g. isolators and circulators) involve inhomogeneous EM fields, complex material behavior, and the presence of a permanent magnetostatic field that affects the electron dynamics [17]. As a consequence, a more sophisticated approach is required in order to obtain accurate simulations. For instance, codes based on the EM particle-in-cell (EM-PIC) method have been successfully used in [18] and [19] where the multipactor discharge dynamics between ferrite and metal have been investigated for several circulators operating in S-band (around $3 \mathrm{GHz}$ ). Furthermore, multipactor discharge can also take place between two ferrite disks. This situation has, in fact, been recently studied for a circulator operating at $7 \mathrm{GHz}$ [20].

More recently [21], the multipactor effect between two ferrite samples, made of a garnet doped with Holmium used in a two-port isolator working at $10.75 \mathrm{GHz}$, was studied with an accurate electron tracking code (ETC), previously employed with dielectric materials [22]. In this context, therefore, the objective of this expanded work is to validate such three dimensional (3D) EM-based PIC code with a measurement campaign of the multipactor discharges between ferrite disks. The devices used to this end are based on two non-reciprocal microwave components: a real circulator operating in the Lband frequency range (for satellite navigation applications) and an isolator for S-band satellite transceivers.

To carry out the measurement campaign, two ferrite-loaded waveguide devices operating in the L- and S-bands, respectively, are proposed. The detailed design procedure of both structures, based on a full-wave EM-based software tool including also the magneto-static circuits for the proper magnetization of the ferrite samples, is fully described. Furthermore, to obtain realistic simulation results, measured values of the secondary electron yield (SEY) coefficients of the ferrite materials have been used. The paper is concluded with the comparison between the experimental results obtained and the ETC simulation results.

\section{FERRITE TeSt DEVICE}

\section{A. Device Description}

The main objective of this work is the experimental characterization of the multipactor behavior of the two ferrite materials described in TABLE I, namely, G-1200 (L-band) and G-4260 (S-band) doped, respectively, with GadoliniumAluminum and Holmium [2]. These ferrites are made of high performance polycrystalline microwave garnets, which, based on their respective linewidth values (see TABLE I), are suitable for moderate-to-wide bandwidth applications. To this end, two new dedicated test devices have been designed, one for each ferrite sample. The L-band device has been designed avoiding the use of a central low-pass section, like the one proposed in [21] for X-band ferrites. Both L- and S-band devices are excited with a more compact and convenient coaxial excitation.

TABLE I

RELEVANT PARAMETERS OF THE L-BAND G-1200 AND S-BAND G-4260 FERRITES OF THIS WORK.

\begin{tabular}{|c|c|c|}
\hline Parameter & G-1200 & G-4260 \\
\hline Saturation Mag. $(\mathrm{G}, \mathrm{T})$ & $1200,0.12$ & $550,0.05$ \\
\hline Lande g-Factor & 1.98 & 2.00 \\
\hline Line Width $(\Delta \mathrm{H})(\mathrm{Oe}, \mathrm{kA} / \mathrm{m})$ & $<60,4.8$ & $<120,9.5$ \\
\hline Dielectric Constant & 15.1 & 14.4 \\
\hline Dielectric Loss Tangent & 0.0002 & 0.0002 \\
\hline Curie Temp $\left({ }^{\circ} \mathrm{C}\right)$ & 260 & 180 \\
\hline Remanent Induction $\mathrm{Br}(\mathrm{G}, \mathrm{T})$ & $795,0.08$ & $280,0.03$ \\
\hline Coercitive force Hc $(\mathrm{Oe}, \mathrm{A} / \mathrm{m})$ & $0.83,66.1$ & $0.80,63.7$ \\
\hline Initial Permeability $\mu_{0}$ & 65 & 28 \\
\hline
\end{tabular}

The ferrite samples investigated in this work are thin disks of $1 \mathrm{~mm}$ in height. The disks will be placed inside the rectangular waveguide devices where the RF electric field is maximum. The diameter of each ferrite disk, the specific location within the waveguides, and the magneto-static biasing field, will be optimized in order to guarantee that the multipactor effect will take place only between the two ferrite disks.

For the L-band case, the RF electric field will be amplified by the resonant mode of the ferrite disks (optimum diameter $80 \mathrm{~mm}$ ), which is the classical configuration used in the practical implementation of commercial circulators [15]. The S-band ferrite disks (optimum diameter $15 \mathrm{~mm}$ ) will be magnetized in order to work close to the gyromagnetic (or ferromagnetic) resonance, which is the typical operation point for resonant isolators based on ferrite slabs [8].

\section{1) L-Band Ferrite Test Device}

For L-band, the ferrite test device (L-FTD) chosen is an asymmetric transformer in rectangular waveguide technology (see Fig. 1). The dimensions of this device for length, width and height are $709.57 \mathrm{~mm}, 220 \mathrm{~mm}$ and $85 \mathrm{~mm}$, respectively. The asymmetric configuration is chosen because it is very easy to manufacture. 


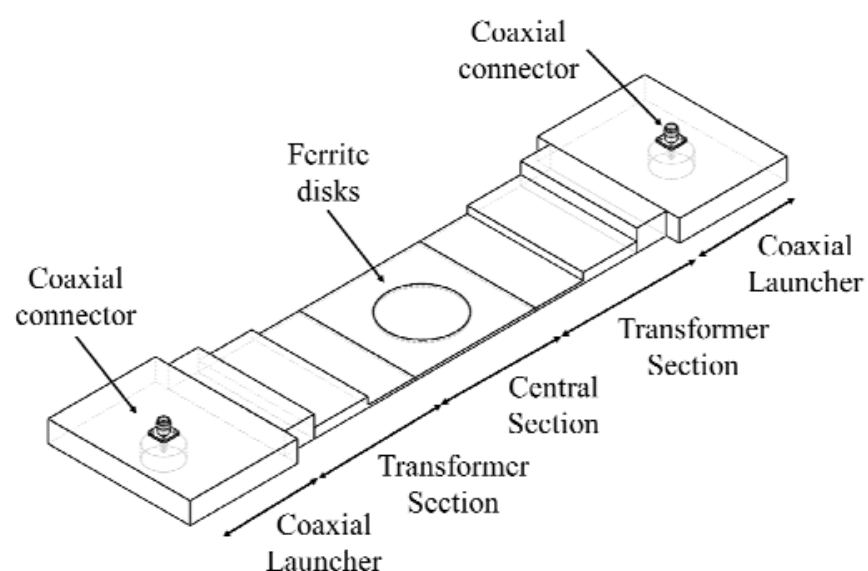

(a)

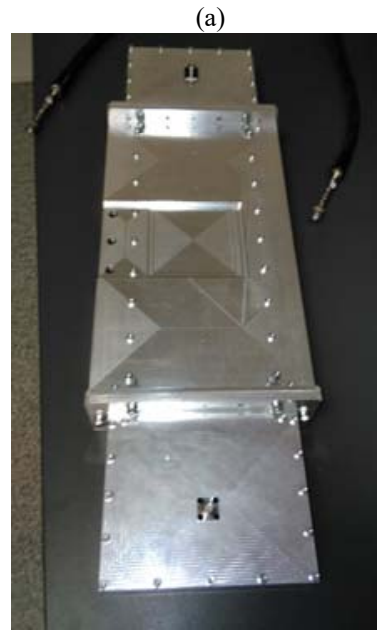

(b)

Fig. 1. L-band ferrite test device. (a) 3D-view of the asymmetric transformer. (b) Manufactured prototype.

As shown in Fig. 1, the two main parts of the L-FTD are the input and output launchers (coaxial to waveguide transition), and the input and output transformers (TRFs) connected to the central section containing the two ferrite disks. In this central section, of $3.0 \mathrm{~mm}$ in high, the RF electric field has the highest magnitude. It is therefore the ideal location for the ferrite samples, since multipactor discharges are more prone to be generated there.

The multipactor characterization of the L-band ferrite sample (G-1200) will be carried out at $1.584 \mathrm{GHz}$. At this operating frequency, the ferrite must be biased well above saturation. In our case, as indicated in TABLE I, the magnetostatic biasing field must, therefore, be higher than 1200 Oe $(95.5 \mathrm{kA} / \mathrm{m})$. If the ferrite operates below saturation, the interaction with the microwave signal is strongly reduced, and the insertion losses becomes very high (more appropriate as absorbing materials [3]).

In this case, we have chosen a magneto-static biasing field $\left(H_{0}\right)$ of intensity equal to $1600 \mathrm{Oe}(127.4 \mathrm{kA} / \mathrm{m})$, which is well above the saturation magnetization level $\left(M_{S}\right)$ of 1200 Oe $(95.5 \mathrm{kA} / \mathrm{m})$ for the $\mathrm{G}-1200$ ferrite (TABLE I).

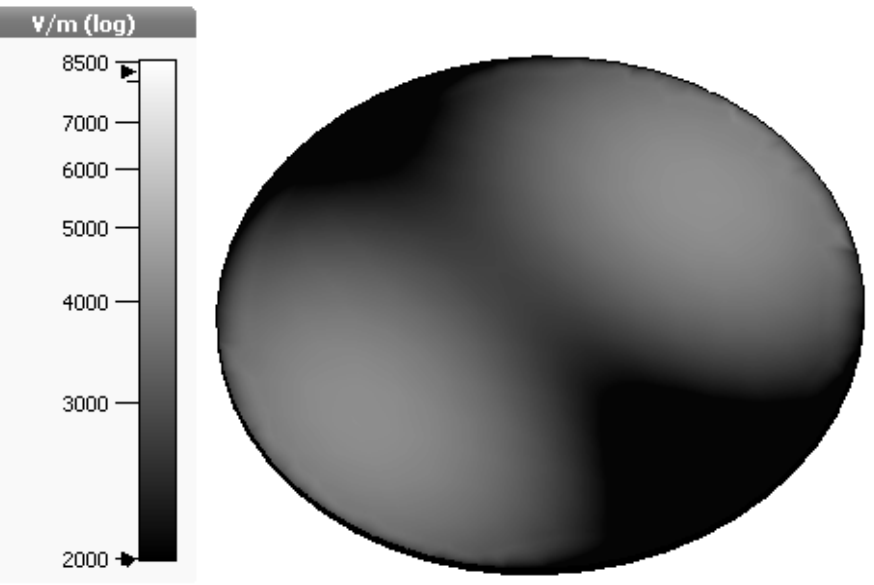

Fig. 2. Electric Field distribution normal to the L-band ferrite surface at the frequency of $1.584 \mathrm{GHz}$, with a magneto-static biasing field level of $1600 \mathrm{Oe}$ $(127.4 \mathrm{kA} / \mathrm{m})$.

With this knowledge, we can now use Kittel's equation with demagnetization factors to compute the ferromagnetic resonant frequency of a thin ferrite disk [8]:

$$
\omega_{\mathrm{r}}=\sqrt{\omega_{0}\left(\omega_{0}+\omega_{\mathrm{m}}\right)}
$$

where $\omega_{0}$ is known as the Larmor (or precession) frequency, defined as $\omega_{0}=\gamma H_{0}, \omega_{\mathrm{m}}=\gamma M_{\mathrm{s}}$ (where $H_{0}$ and $M_{s}$ are given in Oe), and where $\gamma$ the gyromagnetic ratio (equal to $1.759 \cdot 10^{11} \mathrm{~s}^{-1} \mathrm{~T}^{-1}$ or $\left.\gamma /(2 \pi)=2.8 \mathrm{MHz} / \mathrm{Oe}\right)$.

In our case, after substituting these values into eq. (1), the Kittle's frequency is $f_{\mathrm{r}}=5.925 \mathrm{GHz}$, which is well above the L-band operating frequency of $1.584 \mathrm{GHz}$ that we have selected. As a consequence, the G-1200 ferrite will be saturated and will operate below its corresponding ferromagnetic resonant frequency. This is indeed the typical configuration used in microwave circulators. Furthermore, the dimensions of the ferrite disks are chosen to make the $\mathrm{TM}_{110}$ mode resonant at a frequency close to the operating frequency of $1.584 \mathrm{GHz}$, thus amplifying the maximum value of the RF electric field between the two ferrites, and achieving, at the same time, a non-reciprocal response. This is the exact same resonant behaviour used in [18] and [19] for studying the multipactor effect between a ferrite sample and a metallic wall for S-band circulators operating at frequencies close to $3 \mathrm{GHz}$.

In our case the multipactor effect will occur between the two ferrites (and not between ferrite and metal as in [18] and [19]). However, the presence of a resonance is a good mechanism to obtain high levels of RF electric field between the two ferrite disks. In Fig. 2 we show the electric field distribution normal to the surface of one ferrite sample at $1.584 \mathrm{GHz}$. As we can clearly see, two maximum areas of the electric field distribution correspond to the resonant $\mathrm{TM}_{110}$ mode.

All relevant parameters for the L-band case are given in TABLE II, and Fig. 3. It is important to note that their exact location is inside the central section of the device. One disk is glued on the top inner surface of the RWG, and the other is TABLE II 
DIMENSIONS OF THE HOUSING WAVEGUIDE AND FERRITE DISKS FOR L-BAND.

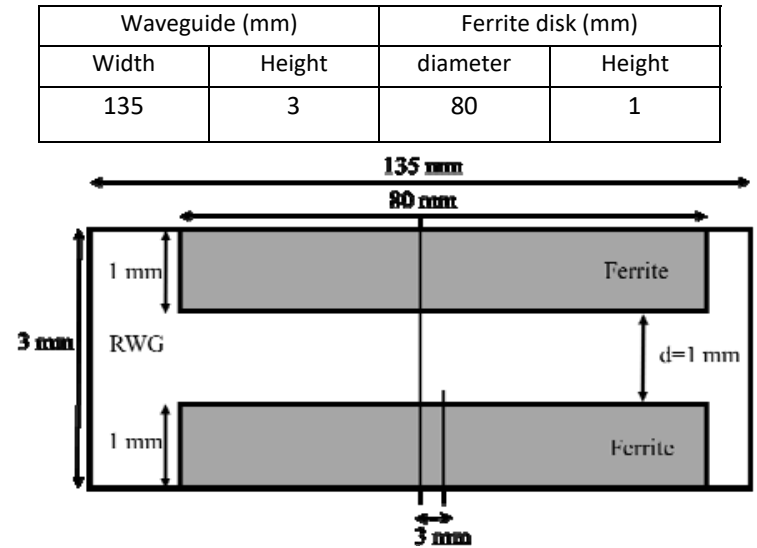

Fig. 3. L-band ferrite disks inside the RWG central section with gap of $d=$ $1.0 \mathrm{~mm}$. Ferrite disk diameters are $80 \mathrm{~mm}$. The centers of the ferrite disks are $3 \mathrm{~mm}$ offset with respect to the center of the RWG.

glued to the opposite bottom surface. The ferrites location, their diameters and the strength of the magneto-static biasing field have all been optimized using full-wave EM simulations (more details will be given in section II.B). As shown in Fig. 3 , the centers of both ferrite disks are $3 \mathrm{~mm}$ offset with respect to the center of the RWG cross-section. This is done to better excite the selected resonant mode and to ensure a nonreciprocal response at the operating microwave frequency. An air gap of $1 \mathrm{~mm}$ is left between the two ferrite samples.

\section{2) S-Band Ferrite Test Device}

The S-band ferrite test device (S-FTD), on the other hand, is based on a corrugated low-pass filter structure, which is connected to the input and output sections of the device through two asymmetric transformers. The complete test device is implemented in rectangular waveguide technology, as shown in Fig. 4. Corrugated low-pass filters do usually have a maximum value for the electric field intensity in their central section. This is therefore the ideal location to place the ferrites. Again, for manufacturing simplicity, an asymmetric configuration is chosen for both for the low-pass filter and transformer sections.

As shown in Fig. 4, the proposed S-FTD is composed of three parts, namely, input and output launchers (the coaxial to waveguide transitions), the input and output TRFs and the corrugated low-pass filter (LPF) central section. The final dimensions for the length, width and height of the S-FTD are $626 \mathrm{~mm}, 130 \mathrm{~mm}$ and $70 \mathrm{~mm}$, respectively. The central part of the asymmetric corrugated LPF (see Fig. 4) has a total height of $2.5 \mathrm{~mm}$ (which is the lowest value for all rectangular waveguide heights in the S-FTD). As a consequence, the central waveguide section is the ideal location for placing the two G-4260 ferrite disks. The magnified value of the RF electric field will help to ignite more easily the multipactor discharges. In the S-FTD case, the multipactor discharge will be characterized at $3.0 \mathrm{GHz}$. Again, at this frequency, the G4260 ferrite material must be biased well above saturation.

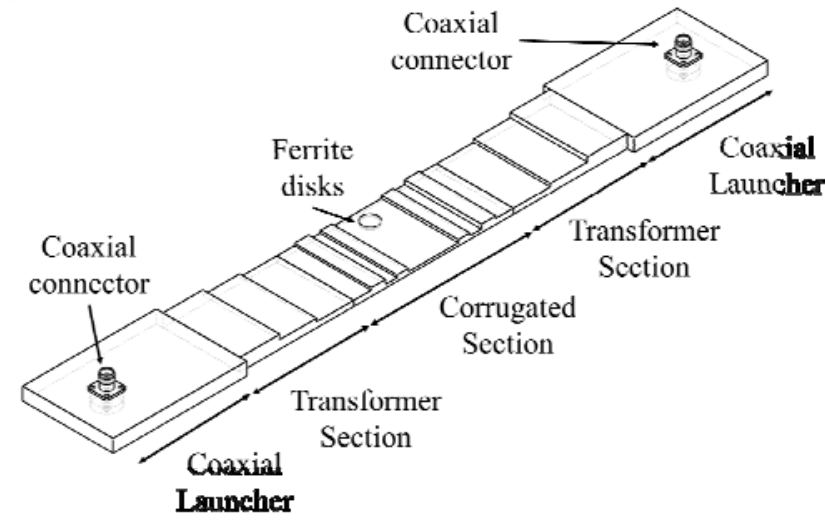

(a)

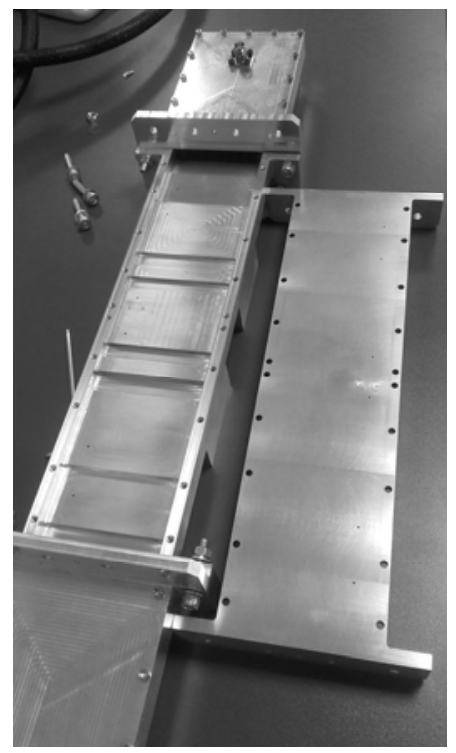

(b)

Fig. 4. S-band ferrite test device. (a) 3D-view of the asymmetric corrugated low-pass filter with transformer sections. (b) Manufactured prototype.

According to TABLE I, the magneto-static biasing field must now be higher than 550 Oe $(43.8 \mathrm{kA} / \mathrm{m})$. However, the aim now is to find a suitable value for the magneto-static biasing field $\left(\mathrm{H}_{0}\right)$ which makes the ferromagnetic resonance frequency (or Kittel's frequency, $f_{\mathrm{r}}=\omega_{\mathrm{r}} / 2 \pi$ ) be equal to $3.0 \mathrm{GHz}$. This will ensure a non-reciprocal ferrite response at the operational frequency. This is indeed the typical operational mode used in microwave isolators.

Making use of all available data in eq. (1), we can easily compute that the requested Larmor frequency value $\left(f_{0}=\omega_{0} / 2 \pi\right)$ will be equal to $2.327 \mathrm{GHz}$. This value corresponds to a bias field $H_{0}=\omega_{0} / \gamma=830$ Oe $(66.1 \mathrm{kA} / \mathrm{m})$, well above the saturation magnetization level $\left(\mathrm{M}_{\mathrm{s}}\right)$ of $550 \mathrm{Oe}$ $(43.8 \mathrm{kA} / \mathrm{m})$ for the $\mathrm{G}-4260$ ferrite (see TABLE I). 
DIMENSIONS OF THE HOUSING WAVEGUIDE AND FERRITE DISKS FOR S-BAND.

\begin{tabular}{|l|c|c|c|}
\hline \multicolumn{2}{|c|}{ Waveguide $(\mathrm{mm})$} & \multicolumn{2}{c|}{ Ferrite disk $(\mathrm{mm})$} \\
\hline Width & Height & diameter & Height \\
\hline 72.14 & 2.5 & 15 & 1 \\
\hline
\end{tabular}

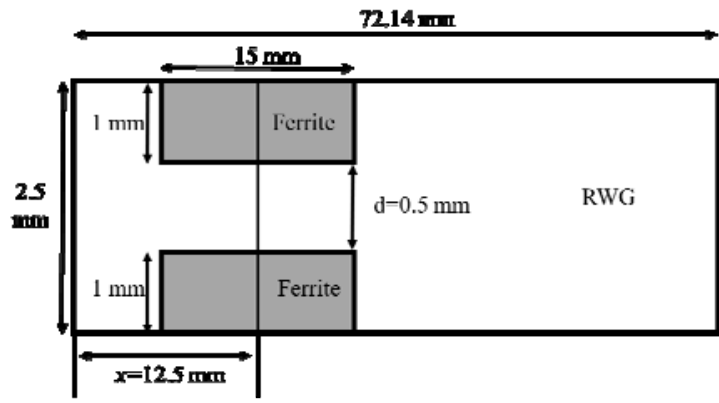

Fig. 5. S-band ferrite disks inside the RWG central section with a gap of $\mathrm{d}=$ $0.5 \mathrm{~mm}$. Ferrite disk are $15 \mathrm{~mm}$ in diameter. The centers of the ferrite disks are located at $12.5 \mathrm{~mm}$ from the left-side wall of the RWG

Although the experimental results for the multipactor effect will be provided only at the single frequency point of $3.0 \mathrm{GHz}$, the S-FTD has been designed (see details in next section II.B) to exhibit a non-reciprocal response over a bandwidth of 100 $\mathrm{MHz}$, and with a $-20 \mathrm{~dB}$ return loss, centered at $3.0 \mathrm{GHz}$.

For the S-Band test, two G-4260 ferrite disks of $15 \mathrm{~mm}$ in diameter and $1 \mathrm{~mm}$ height will be used. One of these samples will be attached on the top inner surface of the central section of the RWG. The other disk will be placed symmetrically on the opposite (bottom) surface. The air gap between the two ferrite disk samples is $0.5 \mathrm{~mm}$. All of the relevant parameters and dimensions are collected in TABLE III. Fig. 5 shows the RWG structure.

In order to excite the non-reciprocal response of the ferrite, with the fundamental mode $\left(\mathrm{TE}_{10}\right)$ of the central RWG section, the ferrite disks must be shifted with respect to the center of the RWG cross-section (variable $x$ in Fig. 5). The optimized value for this design parameter will be obtained with a fullwave EM simulation, as detailed in section II.B. With the optimized topology, and applying the external magneto-static biasing field of $830 \mathrm{Oe}(66.1 \mathrm{kA} / \mathrm{m})$, the S-FTD will operate at $3.0 \mathrm{GHz}$ with a non-reciprocal behaviour identical the one of real microwave resonant isolators.

\section{B. Design Process}

We are now going to describe the design procedure for both the L-FTD and the S-FTD. In both cases we will use commercial full-wave simulators. Details of the required magneto-static biasing circuits will be also given.

\section{1) L-Band Ferrite Test Device}

As it was described in section II.A.1), the L-FTD is composed of two asymmetric impedance transformer sections realized in RWG technology (see Fig. 1), that connect the central section (where the ferrites are located) to the input and

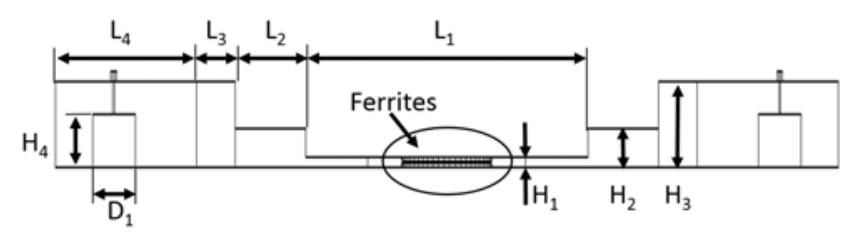

(a)

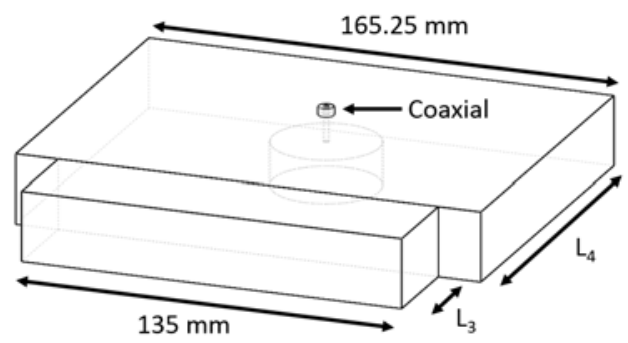

(b)

Fig. 6. Longitudinal view of the L-FTD with ferrite disks in the central part of the device in (a). Dimensions (all in $\mathrm{mm}$ ) are $\mathrm{H}_{1}=3.0, \mathrm{H}_{2}=11.4, \mathrm{H}_{3}=25$, $\mathrm{H}_{4}=15.4, \mathrm{~L}_{1}=250.8, \mathrm{~L}_{2}=62.4, \mathrm{~L}_{3}=34.5, \mathrm{~L}_{4}=125.1, \mathrm{D}_{1}=37.6$. Detailed view of the coaxial to RWG transition in (b).

output coaxial launchers. The design of the impedance transformer is performed with the full-wave commercial tool FEST3D v2018 (Aurora Software and Testing S.L.U., now with CST/3DS). A small air gap of $1 \mathrm{~mm}$ is left between the two L-band ferrite disks. The total height of the central RWG (H1 in Fig. 6) is then $3 \mathrm{~mm}$.

One design aspect that is important to mention is that FEST3D is very accurate and computationally very efficient, but can only analyse homogeneous waveguide sections (i.e. those completely filled with the same material). To complete the design of the whole L-FTD (including the inhomogeneous central section loaded with the two ferrite disks), we have therefore used the 3D full-wave EM code CST Microwave Studio (v2018 from CST/3DS). In particular, CST has been used to provide the frequency response (in terms of scattering parameters) of the central RWG section, including the ferrite disks and the magneto-static biasing fields. The CST results have then been exported to FEST3D to simulate the complete device. Next, the central section has been refined, again with CST, and the results have been again exported to FEST3D. Proceeding iteratively with the two software tool, all design parameters have been successfully finalized, obtaining the desired non-reciprocal behaviour in the entire frequency range of interest (in this case between $1.55 \mathrm{GHz}$ and $1.65 \mathrm{GHz}$ ). The actual values of all the structural parameters is indicated in the caption of Fig. 6. The optimal offset of the ferrite disks is 3 $\mathrm{mm}$ (as described in Fig. 3), and the correct magneto-static biasing field is $1600 \mathrm{Oe}(127.4 \mathrm{kA} / \mathrm{m})$.

The L-FTD has standard TNC female input and output coaxial ports, as shown in Fig. 6. With this configuration, the fundamental mode of the RWG is excited by a current loop. The relevant design parameters are $\mathrm{H}_{4}$ and $\mathrm{D}_{1}$. The 3D boundary integral-resonant mode expansion (3D BI-RME), originally proposed in [23] and now integrated within the software tool FEST3D, has been successfully used to find the 
optimum values of these two variables. The final results obtained are $\mathrm{H}_{4}=15.4 \mathrm{~mm}$ and $\mathrm{D}_{1}=37.6 \mathrm{~mm}$.

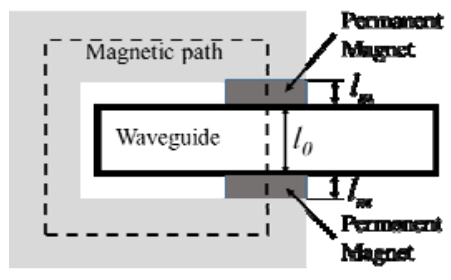

a)

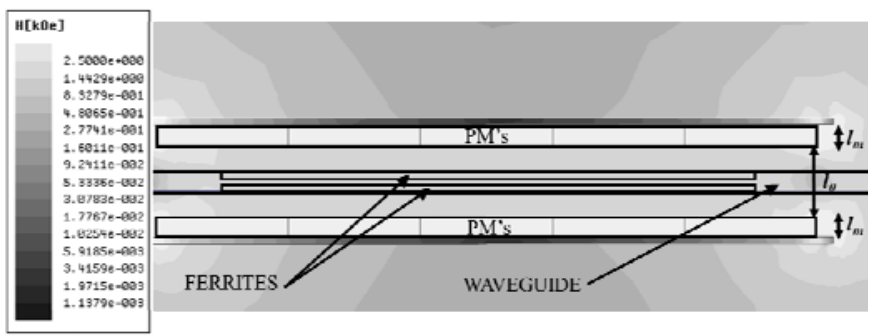

b)

Fig. 7. (a) The "U" shaped magnetic circuit used to magnetize the L-band ferrites. (b) Magneto-static field distribution in the section of interest. The magneto-static biasing field is obtained from PMs made of NdFeB-N35 and the gap between magnets correspons to $l_{0}$.

The required value of the magneto-static biasing field is obtained by using an array of 25 permanent magnets (PMs) of Neodymium-Iron-Boron N-35 (with dimensions of $20 \times 20 \times 3$ $\mathrm{mm}$ ) for each magnetic pole. The two magnetic poles have been placed on the top and bottom surfaces of the L-FTD so that they are close to the ferrite disks. As shown in Fig. 7 (a), the magnetic path (or circuit) is completed with a "U" shaped piece of iron (the core).

The value of the permittivity of the "U" shaped core is higher than the ones of the air and PMs regions. As a consequence, to determine the magnetic reluctance of the whole circuit we need to consider only the air gap and the PMs regions, indicated by $l_{0}$ and $l_{m}$ in Fig. 7(a). Assuming that there are no current sources, we can recall the well-known Ampere's law:

$$
\int_{\mathrm{C}} \vec{H} \cdot \vec{d} l=\iint_{\mathrm{S}} \vec{J} \cdot \vec{d} S=0
$$

and, using the parameters involved in the magnetic circuit using, write explicitly:

$$
H_{0} l_{0}+2 H_{\mathrm{m}} l_{m}=0 \quad \rightarrow \quad l_{0}=-\frac{2 H_{\mathrm{m}} l_{m}}{H_{0}}
$$

From eq. (3), after substituting the known values for the desired magneto-static field (in this case $\mathrm{H}_{0}=1600 \mathrm{Oe}$ (127.4 $\mathrm{kA} / \mathrm{m})$, the height of the PMs $\left(l_{m}\right)$ and their operation point $\left(H_{\mathrm{m}}\right)$, the initial value for the gap length $\left(l_{0}\right)$ is easily obtained. The value of $\left(H_{\mathrm{m}}\right)$ is selected to be approximately half the value of the coercive force of the selected PMs, namely, $\mathrm{H}_{\mathrm{m}}=$ $5500 \mathrm{Oe}(437.8 \mathrm{kA} / \mathrm{m})$. The final value of the gap length $\left(l_{0}\right)$ finally obtained using the commercial software tool Ansys Maxwell 3D/2D (see Fig.7 (b)).

\section{2) S-band Ferrite Test Device}

The most complex part of the S-FTD structure is the central LPF section, where the two ferrite disks are located (see Fig. 4). The LPF section is then connected to the input/output coaxial launchers through two asymmetric TRFs. The topology of the corrugated LPF is shown in Fig. 8. The related design variables are $\mathrm{H} 1$ to $\mathrm{H} 5, \mathrm{~L}_{1}$ to $\mathrm{L}_{4}$ and the exact location of the ferrite disks in the central waveguide section of the LPF. All the variables will be optimized following an iterative procedure, based on alternating simulations with the fullwave tools FEST3D and CST Microwave Studio, like the one described in section II.A.1) for the L-band TRF section.

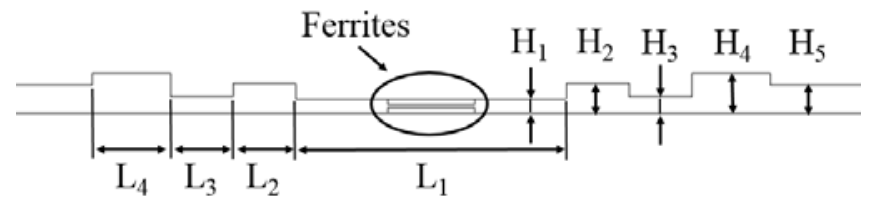

Fig. 8. Longitudinal view of the corrugated LPF of the S-band FTD, with the ferrite disks in the central part of the LPF. Dimensions (all in $\mathrm{mm}$ ) are $\mathrm{H}_{1}=2.5$, $\mathrm{H}_{2}=5.1, \mathrm{H}_{3}=2.9, \mathrm{H}_{4}=6.9, \mathrm{H}_{5}=4.9, \mathrm{~L}_{1}=46.65, \mathrm{~L}_{2}=10.84, \mathrm{~L}_{3}=10.79, \mathrm{~L}_{4}=13.44$.

A key aspect in the design process of the LPF section is to find the optimum position of the ferrite disks (variable $\mathrm{x}$ in Fig. 5), that provides minimum insertion losses (IL) in the direct propagation path, and a maximum attenuation in the reverse propagation direction. According to [8], a good initial solution can be obtained using the following equation:

$$
\tan \left(k_{\mathrm{c}} x\right)= \pm \frac{k_{\mathrm{c}}}{\beta_{0}}
$$

where $k_{\mathrm{c}}$ is the cut-off wavenumber of the central waveguide, and $\beta_{0}$ the propagation constant of the fundamental $\mathrm{TE}_{10}$ mode, defined as $\beta_{0}=\sqrt{k_{0}^{2}-k_{c}^{2}} \quad\left(k_{0}\right.$ is the free-space wavenumber at the central frequency of the S-FTD).

To continue, we used the 3D full-wave software tool CST Microwave Studio to obtain the S-parameters of the central waveguide section of the LPF, including the shifted ferrite disks and the magneto-static biasing fields. The results obtained are then exported to the software package FEST3D, and the optimization of the corrugated LPF dimensions is performed. The objective of the optimization is to obtain a good return loss (RL) level in the entire operational bandwidth (in this case, between $2.95 \mathrm{GHz}$ and $3.05 \mathrm{GHz}$ ). The optimal solution obtained with FEST3D is next simulated with the CST software tool and, if needed, the values of $x$ and $\mathrm{H}_{0}$ are refined. A number of iterations are performed until the desired response for the LPF is obtained. The final geometrical parameters are shown in the captions of Fig. 5 and Fig. 8. The required magneto-static biasing field strength is 830 Oe (66.1 $\mathrm{kA} / \mathrm{m})$. 


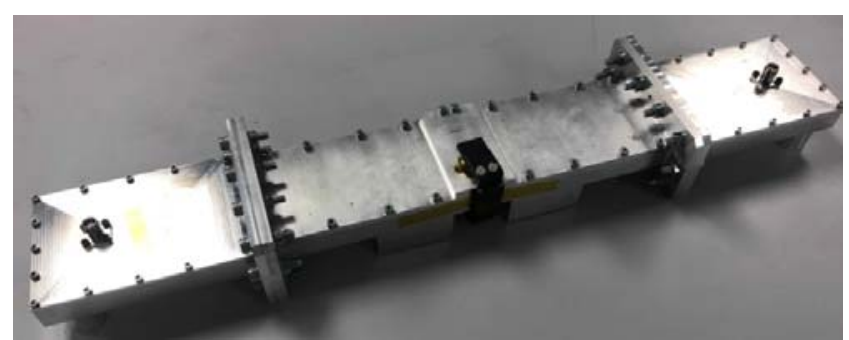

Fig. 9. View of the manufactured S-FTD prototype, including the permanent magnets and the "U" shaped magnetic circuit used to polarize the ferrites.

Once the central section LPF is obtained, the two other elements (TRFs and coaxial launchers) of the S-FTD have been designed using FEST3D. The TRF sections is composed of only two steps to increase the height of the outer waveguide of the LPF (of value $\mathrm{H}_{5}=4.9 \mathrm{~mm}$ ) up to $12 \mathrm{~mm}$ (that is the height of the waveguide hosting the coaxial launcher). As shown in Fig. 4, the TRF sections and the central LPF are manufactured together in one single piece that is connected at both ends to the corresponding input/output coaxial launchers. Again, a current loop configuration is chosen for the transitions from female TNC coaxial connectors to the input/output waveguide housings, thus providing a good behavior in terms of RL for the whole bandwidth of interest (100 MHz around the central frequency of $3 \mathrm{GHz}$ ).

Also in this case, a magneto-static biasing circuit is needed to polarize the S-band ferrite disks so that a non-reciprocal response is obtained. The topology and working mechanisms of the magnetic circuit are the same ones described in section II.B.1). The PMs disks used in this case have a diameter of 20 $\mathrm{mm}$ and a height of $2 \mathrm{~mm}$. They are again made of Neodymium-Iron-Boron N-35. The design of the corresponding magnetic circuit follows the same procedure as the one used for the L-FTD case. The final structure obtained, after integration with the S-FTD, is shown in Fig. 9.

\section{Experimental Validation}

The measured performances of both L-FTD and S-FTD devices are shown in Fig. 10 (L-band) and Fig. 11 (S-band). In both figures, the simulated CST data are represented with dashed lines. Solid lines correspond to experimental data. The curves labelled ISO represent the non-reciprocal response of each FTD, which is computed as the difference (in logarithmic units) between the S-parameters $S_{21}$ (the forward path) and $S_{12}$ (the reverse path). Although both prototypes are made of Aluminium, perfect conductors have been used for all CST simulations.

As we can see in Fig. 10, measured and simulated results are in generally good agreement. However, the measured IL is 1.2 $\mathrm{dB}$ at $1.584 \mathrm{GHz}$, whereas the simulated value is $0.6 \mathrm{~dB}$. Two reasons can explain this difference. The first is that the losses due to conductor material and coaxial connectors have not been included in the CST simulations. The second reason is that there may be a small difference between the simulated and measured contributions of dielectric losses from the ferrite samples. On the other hand, the measured RL is better than 20 $\mathrm{dB}$ in the frequency range of interest around $1.6 \mathrm{GHz}$, and the value of the ISO parameter is $3.3 \mathrm{~dB}$ at the central frequency of operation $(1.6 \mathrm{GHz})$.

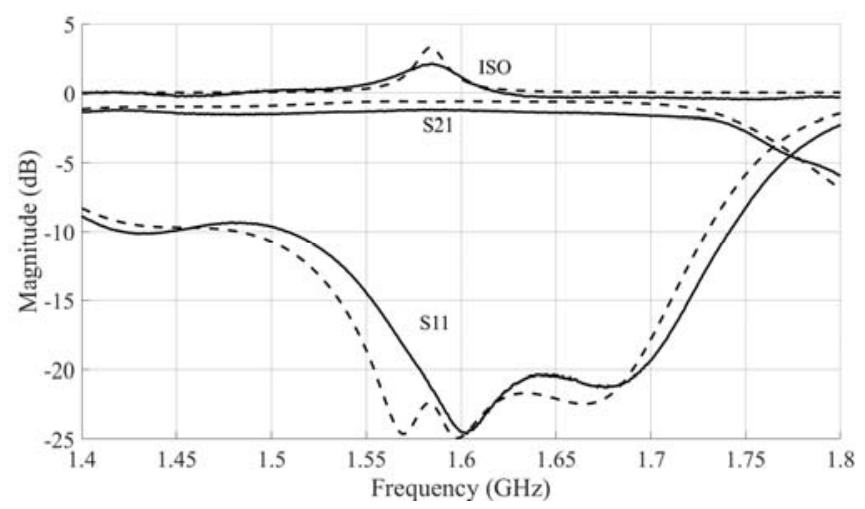

Fig. 10. Frequency responses (S-parameters and isolation) of the L-FTD with magnetized ferrites: simulated data (dashed lines) versus measurements (solid lines)

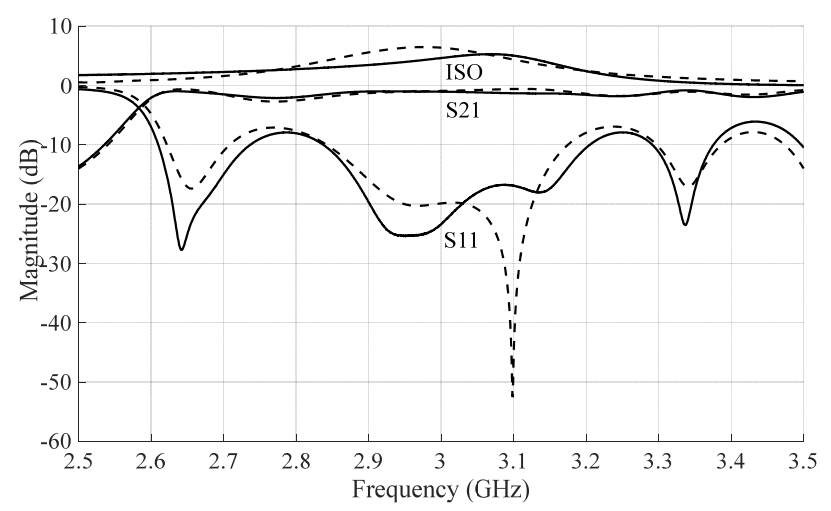

Fig. 11. Frequency responses (S-parameters and isolation) of the S-FTD with magnetized ferrites: simulated data (dashed lines) versus measurements (solid lines).

A reasonably good agreement is also shown in Fig. 11 for the measured and simulated results in the S-FTD case. The ISO parameter shows a maximum value around $3.0 \mathrm{GHz}$, which is the nominal working frequency. The measured $\mathrm{RL}$ is about $20 \mathrm{~dB}$, whereas IL and ISO have values of $1.05 \mathrm{~dB}$ and 4.7 $\mathrm{dB}$, respectively, at $3.0 \mathrm{GHz}$.

The small deviations between measured and simulated results, for both L-FTD and S-FTD, can also be justified as follows. First, the mechanical tolerance in the manufacture of the two prototypes (approximately $150 \mu \mathrm{m}$ ). Second, the deviation between the real and nominal values of the magnetization level of the PMs in the magneto-static biasing circuits.

The next step has been the measurement of the multipactor power thresholds. The RF setups for the two multipactor tests have been designed to operate, at $1.584 \mathrm{GHz}$ (L-band) and 3.0 $\mathrm{GHz}$ (S-band), respectively. The gaps between ferrite disks are $1 \mathrm{~mm}$ at L-band and of $0.5 \mathrm{~mm}$ at S-band. As a consequence, the frequency-gap products are similar for both cases. In particular, we have $1.584 \mathrm{GHz} \times \mathrm{mm}$ for $\mathrm{L}$-band and 1.5 $\mathrm{GHz} \times \mathrm{mm}$ for S-band. It is important to note that the measured return loss for both test devices is fully adequate for performing the multipactor tests at two frequencies of interest. 


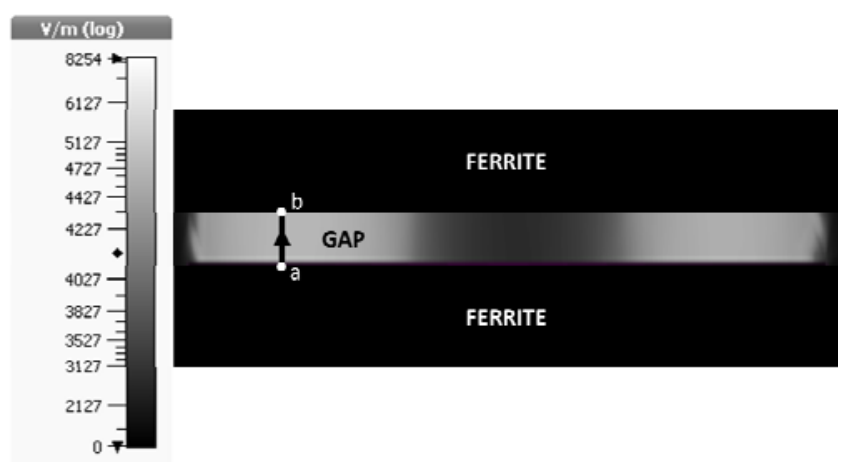

(a)

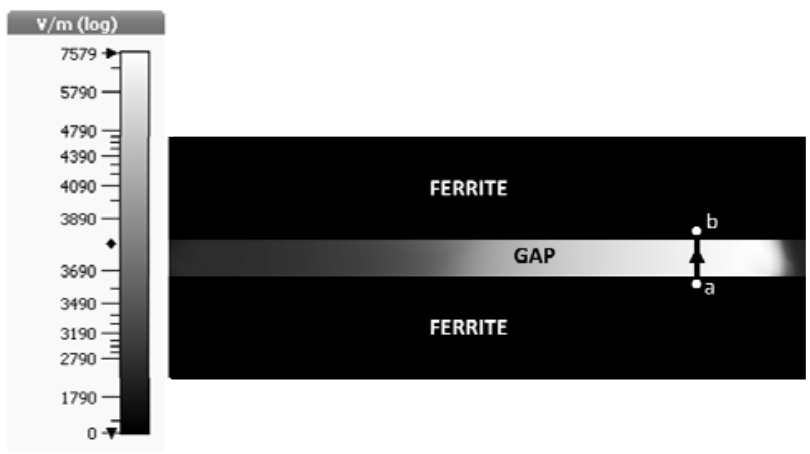

(b)

Fig. 12. (a) Electric filed distribution between ferrite disks for L-FTD at $1.584 \mathrm{GHz}$, and for the S-FTD at $3.0 \mathrm{GHz}$ in (b), where the maximum electric field is located between the two ferrites disks of each device.

Before performing the multipactor tests, we have performed one final simulation using CST Microwave Studio to evaluate the EM fields in the central regions of both FTDs. Fig. 12(a) and (b) show the electric field distribution for the L-FTD and S-FTD, respectively.

As we can see, in both cases the maximum values of the electric field distributions are located between the two ferrite disks. This ensures that the multipactor discharges will indeed take place in the expected regions.

\section{MULTIPACTOR CHARACTERIZATION}

The prediction of the physical location of the multipactor discharge, and the values of the power threshold for the RF input power for each prototype have been carried out using the commercial simulator SPARK3D v2018 (from Aurora Software and Testing S.L.U., now with CST/3DS). This ETC code (see more details in [24]) uses the EM field distributions that have been computed previously with CST Microwave Studio using the final device geometries, including the magneto-static bias.

SPARK3D solves the 3D Lorentz force equation to compute the electron trajectories. It models the interactions between the charged particles and the surfaces of the ferrites and all metals in the FTDs. The electrons can be absorbed, reflected or extract from the surfaces, thus creating new secondary electrons, following the Vaughan model [25]. More details about the physical models used in SPARK3D can be found in
[26]. The number of initial electrons is given as an input parameter to the software tool. We have observed that consistent and convergent results can be obtained starting with 1000 electrons. The multipactor event is automatically detected when the electron population grows exponentially (beyond a certain predefined limit). The code performs a power sweep and determines if a discharge exists or not for each RF input power level. The minimum breakdown threshold is the minimum power level that is able to induce a multipactor discharge.

TABLE IV

SEY PARAMETERS USED IN MULTIPACTOR SIMULATIONS (FROM [27])

\begin{tabular}{|c|c|c|c|}
\hline & $E_{1}(e V)$ & $E_{\max }(e V)$ & $S E Y_{\max }$ \\
\hline G-1200 & 19 & 303 & 3.3 \\
\hline G-4260 & 13 & 372 & 3.3 \\
\hline
\end{tabular}

To simulate correctly the multipactor effect, the ferrite materials under test must be characterized in terms of the SEY coefficient [25]. For this purpose, three main parameters are needed: the energy level of the incident or primary electrons when the SEY coefficient is equal to one $\left(E_{1}\right)$, and the maximum impact energy $\left(E_{\max }\right)$ that provides a maximum value for the SEY coefficient (i.e. SEY max $_{\text {ax }}$. This information has been obtained experimentally, for both the G-1200 and G4260 ferrites, using a pulsed electron irradiation (pulse dose of $1 \mathrm{fC} / \mathrm{cm}^{2}$ ) to avoid charging effects [27]. The data obtained are collected in TABLE IV.

The SEY values are dependent on the particular composition of each material, but also on the surface roughness of the ferrite samples. The higher surface irregularity (roughness) can help trapping some of the emitted secondary electrons, thus providing higher values for $\mathrm{E}_{1}$, and reducing the maximum effective SEY. As we can see in TABLE IV, both ferrite materials have similar values of $E_{1}$ and maximum SEY. It must be noted, however, that ferrite materials can also be considered as dielectrics with magnetic properties. As a consequence, the surface charging process that takes place during the multipactor testing activity may also affect the final result [28].

The results for multipactor tests are usually expressed in terms of the RF input power of the corresponding FTDs. In addition we have also computed the necessary equivalent voltage between ferrite disks for igniting multipactor discharge in the areas of interest. For this purpose, the voltages $\left(V_{a b}\right)$ between points "a" and "b" in Fig. 12 have been computed, for each ferrite, considering an input power level of $1 \mathrm{~W}$. Following then the technique already used in [22] for dielectric materials, and using the simulated results provided by SPARK3D, we have finally obtained the multipactor breakdown voltages in the areas of interest (the gaps between ferrite disks). The results obtained are collected in TABLE V.

Next, we compare in TABLE IV the simulated results (obtained with SPARK3D) for the multipactor threshold values (in terms of RF input power level) with the experimental data. On the bottom of the table we include information about the method used for the practical detection of the multipactor events (in this case, the well-known nulling 
system [9]). As we can see in TABLE VI, an almost perfect agreement is obtained for the L-FTD, thus fully validating the proposed testing structure and the related design procedure. On the other hand, a relatively small difference (about $2 \mathrm{~dB}$ ) has been found in the case of the S-FTD. This small difference, however, is not of particular concern because the European [9] and American [14] standards establish safe margins between simulated and measured data of $8 \mathrm{~dB}$ and $6 \mathrm{~dB}$, respectively. As a consequence, the results obtained fully validate also the S-FTD testing structure and the related design procedure.

TABLE V

RF MULTIPACTOR DISCHARGE SIMULATED RESULTS FOR L- AND S-BANDS

\begin{tabular}{|c|c|c|c|}
\hline Frequency & \multicolumn{3}{|c|}{ SIMULATION } \\
\hline$(\mathrm{GHz})$ & $\begin{array}{c}\text { V at } 1 \mathrm{~W} \\
(\mathrm{~V})\end{array}$ & $\begin{array}{c}\text { Threshold } \\
(\mathrm{W})\end{array}$ & $\begin{array}{c}\text { Threshold } \\
(\mathrm{V})\end{array}$ \\
\hline 1.584 & 5.2 & 124 & 58.4 \\
\hline 3.00 & 7.2 & 122 & 79.5 \\
\hline
\end{tabular}

TABLE VI

RF MULTIPACTOR DISCHARGE EXPERIMENTAL RESULTS FOR L- AND S-BANDS

\begin{tabular}{|c|c|c|}
\hline $\begin{array}{c}\text { Frequency } \\
(\mathrm{GHz})\end{array}$ & $\begin{array}{c}\text { Simulated } \\
(\mathrm{dBW})\end{array}$ & $\begin{array}{c}\text { Discharge } \\
(\mathrm{dBW})\end{array}$ \\
\hline 1.584 & 20.93 & $20.49^{\mathbf{1}}$ \\
\hline 3.00 & 20.86 & $23.01^{\mathbf{1}}$ \\
\hline
\end{tabular}

Triggered Detection Systems:

${ }^{1}$ Nulling system

It must be noted, however, that the origin of the small discrepancies for the S-FTD results can be attributed to uncertainties concerning the SEY properties used in the simulations as compared to the real performance during multipactor testing. In addition, as already mentioned, ferrite samples also show a dielectric behavior. The accumulated charge in their surfaces can modify the interaction with impacting electrons, and, as a consequence, modify the real effective SEY during the experiments. Finally, the manual handling and aging of ferrite samples may also introduce impurities on their surfaces, thus affecting the corresponding SEY values.

Finally, during the multipactor tests performed with both ferrites, the temperature level of the set-ups was monitored and kept constant at about $22{ }^{\circ} \mathrm{C}$. The return loss (RL) levels of the ferrite test devices were also measured during all highpower tests. No significant variations were observed. These results clearly confirm that the ferrites also have a good thermal behavior under high-power levels in the microwave frequency range.

\section{CONCLUSION}

In this work, we have discussed the design of two nonreciprocal waveguide devices, operating in L- and S-bands, for obtaining experimental results of multipactor effects between ferrite samples. To this end, the central section of the test devices have been partially loaded with two G-1200 ferrites samples doped with Gadolinium-Aluminum, and with two G4260 ferrite samples doped with Holmium. The ferrites that are typically used to manufacture circulators and isolators for
L- and S-band space applications. Details for the design of all geometrical parameters has been provided together with the details of the of the required magneto-static biasing circuits.

Experimental results for the RF multipactor threshold levels of both ferrite samples have been obtained for frequency-gap $(f \times d)$ products of $1.584 \mathrm{GHz} \times \mathrm{mm}(\mathrm{G}-1200)$ and $1.5 \mathrm{GHz} \times \mathrm{mm}$ (G-4260). The results obtained have also been compared with simulated results obtained with a commercial ETC software tool using the measured data of SEY properties for both materials. Considering all uncertainties associated to the multipactor breakdown testing procedure, it can be concluded that very good agreement between simulated and experimental results has been indeed obtained for the both the $\mathrm{L}$ and S-band ferrites. The results presented constitute, in our opinion, a very solid base for both design and further investigations in RF discharge effects between ferrite materials used in nonreciprocal microwave components.

\section{ACKNOWLEDGMENT}

The authors would like to acknowledge the Val Space Consortium laboratories for their contribution to this work Laboratories funded by the European Union through the European Regional Development Fund 2014-2020 of the Valencian Community- A way of making Europe.

\section{REFERENCES}

[1] M. Pardavi-Horvath, "Microwave applications of soft ferrites," Journal of Magnetism and Magnetic Materials", vol. 215-216, pp.171-193, Jun. 2000 .

[2] Microwave Garnets, Skyworks Solutions Inc., July 2017.

[3] S. Chakraborty, N. S. Bhattacharyya, and S. Bhattacharyya, "X-band composite microwave absorber using doped strontium ferrite," in 2017 IEEE Applied Electromagnetics Conference (AEMC), Aurangabad, India, Dec. 2017, pp. 1-2.

[4] C. Kittel, "On the theory of ferromagnetic resonance absorption," Phys. Rev., vol. 73, pp. 155-161, Jan. 1948.

[5] A.M. Kroening, "Advances in ferrite redundancy switching for Ka-band receiver applications," Trans. Microw. Theory Techn., vol. 64, no. 6, pp. 1911-1917, June 2016.

[6] Y.J. Cheng, Q.D. Huang, Y.R. Wang, and J.L. Li, "Narrowband substrate integrated waveguide isolators," IEEE Microwave and Wireless Components Letters, vol. 24, no. 10, pp. 698-700, Oct. 2014.

[7] C.E. Fay and R.L. Comstock, "Operation of the ferrite junction circulator," Trans. Microw. Theory Techn., vol. 13, no. 1, pp. 15-27, Jan. 1965.

[8] D.M. Pozar, Microwave Engineering, 4th ed. Hoboken, NJ, USA: Wiley, 2012.

[9] Multipacting Design and Test, document ECSS-20-01A, European Cooperation for Space Standarization (ECSS), ESA-ESTEC, ESA Publication Division, The Netherlands, May 2003.

[10] J.R.M. Vaughan, "Multipactor," IEEE Trans. on Electron Devices, vol. 35, no. 7, pp. 1172-1180, July 1988.

[11] R.A. Kishek, Y.Y. Lau, L. K. Ang, A. Valfells, and R.M. Gilgenbach, "Multipactor discharge on metals and dielectrics: Historical review and recent theories," Phys. Plasmas, vol.5, no.5, pp. 2120-2126, May 1998.

[12] A.J. Hatch and H.B. Williams, "Multipacting modes of high-frequency gaseous breakdown," Phys. Rev., vol. 112, no. 3, p. 681, Nov. 1958.

[13] A. Woode and J. Petit, "Diagnostic investigations into the multipactor effect, susceptibility zone measurements and parameters affecting a discharge," ESA, Noordwijk, The Netherlands, Working Paper 1556, Nov. 1989.

[14] T.P. Graves, "Standard/handbook for radio frequency (RF) breakdown prevention in spacecraft components," The Aerospace Corporation, El Segundo, CA, USA, Aeroesp. Rep. TOR-2014-02198, 2014. 
[15] D. González-Iglesias, B. Gimeno, V.E. Boria, A. Gómez and A. Vegas, "Multipactor effect in a parallel-plate waveguide partially filled with magnetized ferrite," IEEE Trans. Electron Devices, vol. 61, no. 7, pp. 2552-2557, July 2014.

[16] D. González-Iglesias, A. Gómez, B. Gimeno, O. Fernández, A. Vegas, F. Casas, S. Anza, C. Vicente, J. Gil, R. Mata, I. Montero, V.E. Boria and D. Raboso, "Analysis of multipactor RF breakdown in a waveguide containing a transversely magnetized ferrite," IEEE Trans. Electron Devices, vol. 63, no. 12, pp. 4939-4947, Dec. 2016.

[17] V.E. Semenov et al., "Preliminary results on the multipactor effect prediction in RF components with ferrites," in 2013 IEEE 14th International Vacuum Electronics Conference (IVEC), Paris, France, May 2013, pp. 1-2.

[18] Y. Li, W.Z. Cui, Y. He, X.B. Wang, T. Hu and W. Dan, "Enhanced dynamics simulation and threshold analysis of multipaction in the ferrite microwave component," Physics of Plasmas, vol. 24, no. 2, pp. 1-7, Feb. 2017.

[19] Y. Li, D. Wang, M. Yu, Y. He and W. Cui, "Experimental verification of multipactor discharge dynamics between ferrite dielectric and metal," IEEE Trans. Electron Devices, vol. 65, no. 10, pp. 4592-4599, Oct 2018.

[20] T. Rodriguez, K. Shamsaifar and J. Haas, "Design, manufacture and test techniques for multipactor free RF devices," in Proc. of ESA Passive Components Days, ESA-ESTEC, Noordwijk, The Netherlands, Oct. 1214, 2016, pp. 1-19.

[21] J. Vague, V.E. Boria, M. Guglielmi and J.C. Melgarejo, "Multipactor characterization of ferrite materials for space applications," in IEEE MTT-S International Conference on Numerical Electromagnetic and Multiphysics Modeling and Optimization special sesssion in MultiPhysiscs EM-based Techniques for RF High-Power Discharge Effects, Reykjavik, Iceland, Aug. 8-10, 2018, pp. 1-4.

[22] J. Vague, J.C. Melgarejo, M. Guglielmi, V.E. Boria, S. Anza, C. Vicente, R. Moreno, M. Taroncher, B. Gimeno and D. Raboso, "Multipactor effect characterization of dielectric materials for space applications," Trans. Microw. Theory Techn., vol. 66, no. 8, pp. $3644-$ 3655, Aug. 2018.

[23] P. Arcioni, M. Bozzi, M. Bressan, G. Conciauro, and L. Perregrini, "Frequency/time-domain modeling of 3-D waveguide structures by a BIRME approach," Int. J. Numer. Modeling, vol. 15, pp. 3-21, 2002.

[24] S. Anza, C. Vicente, D. Raboso, J. Gil, B. Gimeno and V.E. Boria "Enhanced prediction of multipaction breakdown in passive waveguide components including space charge effects," in IEEE MTT-S Int Microw. Symp. Dig., Atlanta, GA, USA, Sep. 2008, pp. 1095-1098.

[25] J.R.M. Vaughan, "A new formula for secondary emission yield," IEEE Trans. Electron Devices, vol. 36, no. 9, pp. 1963-1967, Sep. 1989.

[26] C. Vicente, M. Mattes, D. Wolk, B. Mottet, H.L. Hartnagel, J.R. Mosig and D. Raboso, "Multipactor breakdown prediction in rectangular waveguide based components," in IEEE MTT-S Int. Microw. Symp. Dig., Long Beach, CA, USA, June 2005, pp. 1055-1058.

[27] "Novel investigation in Multipactor Effect in Ferrite and Other Dielectrics used in High Power RF Space Hardware", European Space Agency (ESA) project, contract no. AO 1-7551/13/NL/GLC.

[28] R. Mata, L. Mercadé, D. Bañón, J.M. Socuellamos, B. Gimeno, V.E. Boria, D. Raboso, "Study of the charge processes involved in the secondary electron emission yield measurements of dielectric materials", in Proc. 9th Int. Workshop on Multipactor, Corona and Passive Intermodulation, ESA-ESTEC, Noordwijk, The Netherlands, April 5-7 2017.

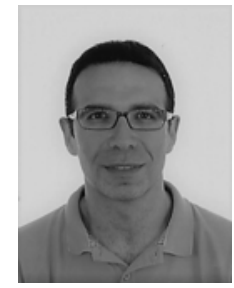

J. Vague was born in Valencia, Spain, in 1970. He received the Electronic Engineering degree from the Universidad de Valencia, Burjassot, Spain, in 2003. He is currently pursuing his $\mathrm{Ph}$. D. degree in Electronic Engineering. His main research interests are the design of microwave passive devices, in particular filters and non-reciprocal devices as well as the improvement in manufacturing processes in the RF and microwave range. He is currently a Technical Researcher in charge Communications, UPV of several laboratories with the Department of

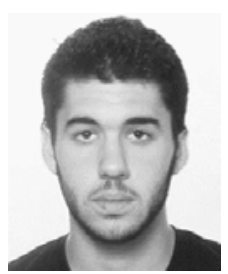

J.C. Melgarejo was born in Alicante, Spain in 1993. He obtained his bachelor's degree in Telecommunications from the Universitat Politècnica de València (UPV) in 2015. From there, he continued his studies with the UPV where he pursued a double Master's in Telecommunications Systems. In 2017, he began his $\mathrm{Ph} . \mathrm{D}$. at the university where his main research interests have been investigating microwave passive devices and new manufacturing techniques for satellite components.

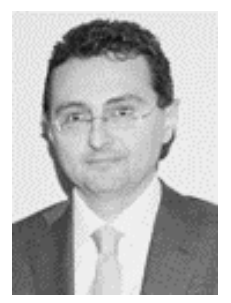

Vicente E. Boria (S'91-A'99-SM'02-F'18) was born in Valencia, Spain in 1970. He received his "Ingeniero de Telecomunicación" degree (with first-class honors) and the "Doctor Ingeniero de Telecomunicación" degree from the Universidad Politécnica de Valencia, Valencia, Spain, in 1993 and 1997, respectively. In 1993 he joined "Departamento de Comunicaciones", Universidad Politécnica de Valencia, where he has been Full Professor since 2003. In 1995 and 1996, he was holding a Spanish Trainee position with the European Space Research and Technology Centre, European Space Agency (ESTEC-ESA), Noordwijk, The Netherlands, where he was involved in the area of EM analysis and design of passive waveguide devices. He has authored or co-authored 10 chapters in technical textbooks, 180 papers in refereed international technical journals, and over 200 papers in international conference proceedings. His current research interests are focused on the analysis and automated design of passive components, left-handed and periodic structures, as well as on the simulation and measurement of power effects in passive waveguide systems.

Prof. Boria has been a member of the IEEE Microwave Theory and Techniques Society (IEEE MTT-S) and the IEEE Antennas and Propagation Society (IEEE AP-S) since 1992. He acts as a regular reviewer of the most relevant IEEE and IET technical journals on his areas of interest. He has been Associate Editor of IEEE Microwave and Wireless Components Letters (2013-2018) and IET Electronics Letters (2015-2018). Presently, he serves as Subject Editor (Microwaves) of IET Electronics Letters, and as Editorial Board member of International Journal of RF and Microwave ComputerAided Engineering. He is also member of the Technical Committees of the IEEE-MTT International Microwave Symposium and of the European Microwave Conference.

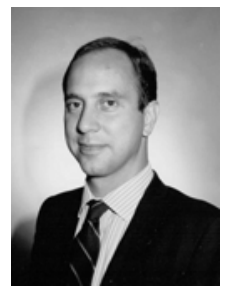

M. Guglielmi (F'13) was born in Rome, Italy, in 1954. He received the Laurea degree in ingegneria elettronica from the University of Rome "La Sapienza," Rome, in 1979 , the M.S. degree in electrical engineering from the University of Bridgeport, Bridgeport, CT, USA, in 1982, and the Ph.D. degree in electrophysics from the Polytechnic University, Brooklyn, NY, USA, in 1986. In 1980, he attended the Scuola di Specializzazione in Elettromagnetismo Applicato, University of Rome "La Sapienza." From 1984 to 1986, he was an Academic Associate with the Polytechnic University, where he was also Assistant Professor from 1986 to 1988. From 1988 to 1989 , he was an Assistant Professor with the New Jersey Institute of Technology, Newark, NJ, USA. In 1989, he joined the RF System Division, European Space Agency, European Space Research and Technology Centre (ESTEC), Noordwijk, The Netherlands, as a Senior Microwave Engineer, where he was in charge of the development of microwave filters and electromagnetic simulation tools. In 2001, he became the Head of the Technology Strategy Section, ESTEC, where he contributed to the development of management processes and tools for the formulation of a European strategy for space technology research and development. Dr. Guglielmi retired from ESA in 2014, and is currently an invited senior researcher with the Polytechnic University of Valencia, Valencia, Spain. Dr. Guglielmi was the recipient of a Fulbright Scholarship in Rome, Italy, in 1981, and the Halsey International Scholarship Programme of the University of Bridgeport, Bridgeport, CT, USA. Dr. Guglielmi has been elevated to the grade of Fellow of the IEEE in January 2013 "For contributions to multimode equivalent networks and microwave filter design", 


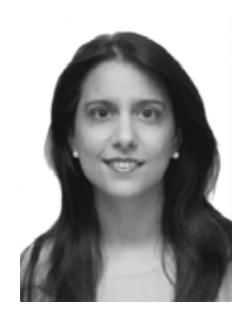

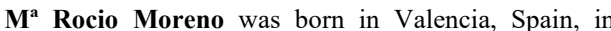
1982. She received the Telecommunications Engineering degree from the Universitat Politècnica de València (UPV), Valencia, Spain, in 2009. From 2008 to 2011 she worked as a researcher with the UPV in the field of the Remote Sensing. In 2012 she started to work in the High Power RF Laboratory of Val Space Consortium as Testing Engineer. Her main testing interest areas are passive intermodulation products, Multipactor, Corona and power handling.

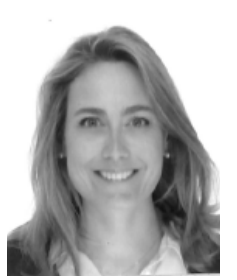

Marta Reglero was born in Alicante, Spain on July 6 , 1982. She received the Telecommunications Engineering degree from the Universitat Politècnica de València (UPV), Valencia, Spain, in 2008. From 2006 to 2008 she was a Fellow Researcher with the Institute of Telecommunications and Multimedia Applications (iTEAM), Universitat Politècnica de València (UPV) and with the Department of Applied Physics Electromagnetism and the Institute of Materials Science (ICMUV), Universitat de València (UVEG). Since 2008, she is a Technical Researcher at iTEAM, UPV. And since 2010, she is a Laboratory Engineer at ESA-Val Space Consortium (VSC). Her current research interests are focused on the analysis of effects of high power microwave devices.

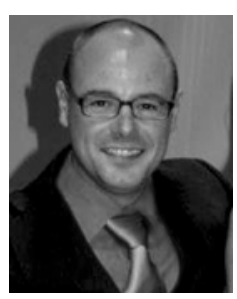

Rafael Mata received the Physics degree and the Ph.D. degree from the University of Valencia, Valencia, Spain, in 2006 and 2011, respectively.

He was a Researcher/Technician with the Val Space Consortium in 2012. His current research interests include the secondary electron emission properties, outgassing, and venting processes in RF high power space materials.

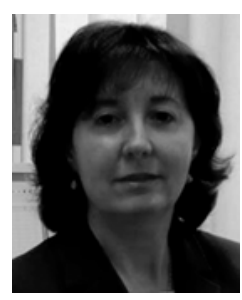

Isabel Montero is currently a Research Professor of the Spanish National Research Council (CSIC). She is the Head of the Group Surface Nanostructuring for Space and Terrestrial Communications with the Materials Science Institute of Madrid. She is the Director of the Spanish Laboratory on Secondary Electron Emission withCSIC. She is an Expert in surface spectroscopic techniques and in low secondary electron emission surfaces and coatings.

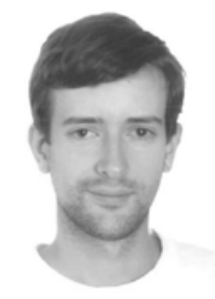

Daniel González-Iglesias received the Licenciado degree in physics and the master's degree in advanced physics from the Universidad de Valencia, Valencia, Spain, in 2010 and 2011, respectively, where he is currently pursuing the Ph.D. degree in physics.

His current research interests include multipacting simulation of RF high-power passive components.

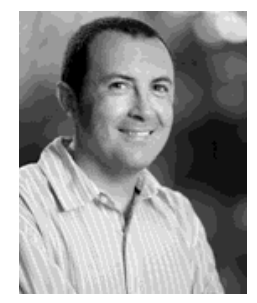

Benito Gimeno Martínez (M’01) was born in

Valencia, Spain, on January 29, 1964. He received the Licenciado degree in physics and the Ph.D. degree from the Universidad de Valencia, Burjassot, Spain, in 1987 and 1992, respectively. He was a Fellow with the Universidad de Valencia from 1987 to 1990. Since 1990, he has been an Assistant Professor with the Departamento de Física Aplicada y Electromagnetismo and the Instituto de Ciencia de Materiales (ICMUV), Universidad de Valencia, where he became an Associate Professor in 1997. During 1994-1995, he was with the European Space Research and Technology Centre, European Space Agency, as a Research Fellow. In 2003, he obtained a fellowship from the Spanish Government for a short stay (three months) at the Universita degli Studi di Pavia, Pavia, Italy, as a Visiting Scientific. His current research interests include computer-aided techniques for analysis of microwave and millimeter-wave passive components for space applications, waveguides, and cavity structures, including dielectric objects, electromagnetic bandgap structures, frequency-selective surfaces, and nonlinear phenomena appearing in power microwave subsystems (multipactor effect, corona effects, and passive intermodulation phenomena).

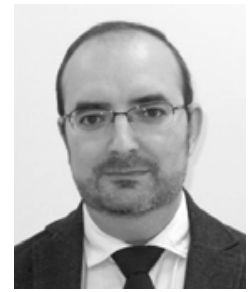

Álvaro Gómez was born in Santander, Spain, in 1976. He received the Licenciado en Ciencias Físicas and Ph.D. degrees from the Universidad de Cantabria, Santander, Spain, in 2000 and 2005, respectively. He joined the Departamento de Ingeniería de Comunicaciones, Universidad de Cantabria, in 2000, where he became a Profesor Titular de Universidad in 2017. His current research interests include electromagnetic propagation in complex materials and numerical methods in electromagnetics.

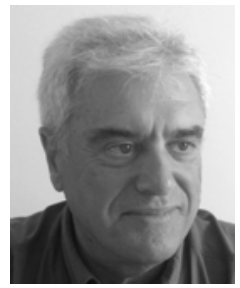

Ángel Vegas (M'98) received the Ph.D. degree in physical sciences from the University of Cantabria, Santander, Spain, in 1983.

$\mathrm{He}$ is currently a Full Professor of Electromagnetics with the University of Cantabria, where he is the Head of the Electromagnetics Group. His current research interests include the electromagnetics of complex materials, computer methods in electromagnetism, and microwave measurements.

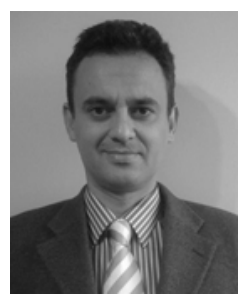

David Raboso received the Degree in physics from the Autonomous University of Madrid, Madrid, Spain and the master's degree in space engineering from the University of Delft, Delft, The Netherlands. In 1992, he joined the European Space Agency, The Netherlands, where he became responsible for all activities related to RF breakdown in space microwave components. He has co-authored over 100 articles in prestigious journals and a co-inventor of nine patents. 